\title{
Linear polyethylenimine-decorated gold nanoparticles: One-step electrodeposition and studies of interaction with viral and animal proteins
}

\author{
Juan M. Lázaro-Martínez a, b, *, Agustín J. Byrne ${ }^{\text {a }}$, Enrique Rodríguez-Castellón ${ }^{\text {b }}$, \\ Julieta M. Manrique ${ }^{\mathrm{c}, \mathrm{d}}$, Leandro R. Jones ${ }^{\mathrm{c}, \mathrm{d}}$, Viviana Campo Dall' Orto ${ }^{\mathrm{e}, * *}$ \\ ${ }^{a}$ Universidad de Buenos Aires - CONICET, Facultad de Farmacia y Bioquímica, Instituto de Química y Metabolismo del Fármaco (IQUIMEFA), Departamento \\ de Química Orgánica, Junín 956, CABA, Argentina \\ b Departamento de Química Inorgánica, Cristalografía y Mineralogía, Facultad de Ciencias, Universidad de Málaga, Campus de Teatinos, Málaga 29071, \\ Spain \\ ${ }^{\mathrm{c}}$ Laboratorio de Virología y Genética Molecular, Facultad de Ciencias Naturales y Ciencias de la Salud (FCNyCS), Universidad Nacional de la Patagonia San \\ Juan Bosco (UNPSIB), 9 de Julio y Belgrano s/n (9100), Trelew, Chubut, Argentina \\ d Consejo Nacional de Investigaciones Científicas y Técnicas, Avenida Rivadavia 1917, C1083ACA Buenos Aires, Argentina \\ e Universidad de Buenos Aires - CONICET, Facultad de Farmacia y Bioquímica, Instituto de Química y Metabolismo del Fármaco (IQUIMEFA), Departamento \\ de Química Analítica y Fisicoquímica, Junín 956, CABA, Argentina
}

\section{A R T I C L E I N F O}

\section{Article history:}

Received 3 September 2018

Received in revised form

14 January 2019

Accepted 27 January 2019

Available online 29 January 2019

\section{Keywords:}

Linear polyethylenimine

Simian immunodeficiency virus envelope

glycoprotein

Gold nanoparticles

Bovine serum albumin

Pulsed electrochemical techniques

\begin{abstract}
A B S T R A C T
Polyethylenimine (PEI)-decorated gold nanoparticles (AuNP) were electrodeposited on conductive surfaces in one-step procedure. Solution-state NMR evidenced that chloride from PEI.HCl was partially exchanged by $\mathrm{AuCl}_{4}^{-}$prior to AuNP formation. XPS studies indicated the presence of $\mathrm{Au}^{\circ}$ together with the interaction between AuNP with nitrogen atoms of the PEI polymer. The particle size by DLS was $49 \mathrm{~nm}$. The electrochemical behavior of bare electrode and of glassy carbon electrode modified with PEIdecorated AuNP was compared using $\left[\mathrm{Fe}(\mathrm{CN})_{6}\right]^{3-/ 4-}$ redox probe, to determine the potential role of the nanomaterial and of the polymer in the detection of proteins. The most relevant experimental variables from cyclic voltammetry (CV), square-wave voltammetry (SWV) and electrochemical impedance spectroscopy (EIS) were used for the characterization of protein uptake. The adsorption by electrostatic interaction between the biomolecules and the positively charged polymer $\left(\mathrm{PEIH}^{+}\right)$affected negatively the current response (Ip) of the probe, especially when the negatively charged protein was involved. This platform resulted adequate to immobilize proteins and to characterize this process, for further applications as a tool in bioanalysis or biotechnology.
\end{abstract}

๑) 2019 Elsevier Ltd. All rights reserved.

\section{Introduction}

Surface modification is usually addressed to improve or to impart new interface properties with biomedical, synthetical or

\footnotetext{
* Corresponding author. Universidad de Buenos Aires - CONICET, Facultad de Farmacia y Bioquímica, Instituto de Química y Metabolismo del Fármaco (IQUIMEFA), Departamento de Química Orgánica, Junín 956, CABA, Argentina.

** Corresponding author. Universidad de Buenos Aires - CONICET, Facultad de Farmacia y Bioquímica, Instituto de Química y Metabolismo del Fármaco (IQUIMEFA), Departamento de Química Analítica y Fisicoquímica, Junín 956, CABA, Argentina.

E-mail addresses: lazarojm@ffyb.uba.ar (J.M. Lázaro-Martínez),vcdall@ffyb.uba. ar (V. Campo Dall' Orto).
}

(bio)sensing purposes [1-4]. The coverage of gold nanoparticles (AuNP) with (bio)polymers which can be further functionalized, is a powerful strategy in the design of platforms with controlled physico-chemical properties. These composites have good stability based on dispersive or van der Waals, electrostatic, hydrogen or covalent bonds [5]. In the broad context of nanostructures applicability, liposomal stabilization [6], efficiency in ion recovery [7], effectiveness in gene delivery [8], or palladium nanocatalysts activity enhancement [9], could be achieved by nanosurface coverage with amphiphilic/hydrophylic polymers. When the polymer around the NPs presents amino groups, it can be activated by means of glutaraldehyde, and linked to basic molecules such as receptors, antigens or enzymes with analytical or (bio)medical purposes [10]. 
AuNP can be chemically synthesized from $\mathrm{HAuCl}_{4}$ in the presence of a reducing agent and ionic macromolecules that stabilize the colloid and prevent from sedimentation [11], or to be used in biosensing [12-14]. Another approach involves the electrodeposition of gold nanostructures (AuNS) from $\mathrm{HAuCl}_{4}$ solution on highly rough electrode surfaces [15], or on polymer-modified surfaces $[16,17]$. A one-step electrosynthesis of AuNP decorated with chitosan (CS, a basic polymer) was made by mixing $\mathrm{HAuCl}_{4}$ and $\mathrm{CS}$ in the solution where the working electrode was polarized at negative potential [18,19].

In this work, we used the one-step strategy of AuNP electrodeposition and simultaneous modification with a hydrophylic polymer. The gold nanoparticles (AuNP) modified with linear 87kDa polyethylenimine (PEI) were deposited on a conducting surface by application of a reductive potential in the presence of $\mathrm{Au}(\mathrm{III})$ and the polymeric ligand. Then, the attached PEI molecules were activated with GA in order to immobilize proteins. Bovine serum albumin (BSA; $66 \mathrm{kDa}$; isoelectric point: 4.7) and a recombinant envelope protein of Simian Immunodeficiency Virus (SIVgp120; predicted molecular mass of $65 \mathrm{kDa}$, theoretical isoelectric point: 8.11) resulted covalently anchored under this procedure. The methods selected to monitor the efficiency of surface modification were cyclic voltammetry (CV), square-wave voltammetry (SWV) and electrochemical impedance spectroscopy (EIS), which could reveal diffusion and/or kinetics constrains or enhancement upon addition of modifier components.

A modified-electrode surface can be able to catalyze the electrochemical reaction of a redox probe present in the measuring solution, and EIS is a powerful methodology to study these processes. One of the relevant measured parameters could be the charge transfer resistance $\left(R_{c t}\right)$, the real component of impedance at low frequency values. The interaction of the modifying layer with a biomolecule is expected to cause an increase in $R_{c t}$ as the faradaic reaction of the redox probe becomes increasingly hindered. Sometimes the interaction is much complex, affecting also the diffusion of the probe or even the capacitance of the conducting surface. The redox probe has to be chosen considering that these species must have no effects on the stability and the activity of the electrode assembly. $\left[\mathrm{Fe}(\mathrm{CN})_{6}\right]^{3-/ 4-}$ is an outer-sphere redox probe of somewhat unique surface sensitivity which can generate a complicated behavior, reason by which the contact time between this redox couple and gold electrodes must be minimal [20]. SWV is another frequency dependent electrochemical technique, in which the enhanced faradic component of the current has both anodic and cathodic contributions [21]. This is equivalent to using low frequencies to estimate $R_{c t}$ in EIS [22].

The combination of the information collected from these studies supported the hypothesis of a versatile platform for biomolecules immobilization and/or sensing. The response to different stimuli on the modified layer provided the most relevant experimental variables to evidence interactions between protein and polymeric ligand. The effect of chemical properties was also studied and the nature of the interactions was discussed.

\section{Experimental}

\subsection{Reagents}

Potassium hexacyanoferrate(II) trihydrate, 98.5-102.0\% $\left(\mathrm{K}_{4} \mathrm{Fe}(\mathrm{CN})_{6} \cdot 3 \mathrm{H}_{2} \mathrm{O}\right)$, potassium hexacyanoferrate $(\mathrm{III})\left(\mathrm{K}_{3} \mathrm{Fe}(\mathrm{CN})_{6}\right)$, hydrogen tetrachloroaurate(III) trihydrate $\left(\mathrm{HAuCl}_{4} \cdot 3 \mathrm{H}_{2} \mathrm{O}, 99.9 \%\right)$, 4-(2-hydroxyethyl)piperazine-1-ethanesulfonic acid (HEPES) $>99.5 \%$, glutaraldehyde solution Grade I 70\% wt in $\mathrm{H}_{2} \mathrm{O}$, and bovine serum albumin (BSA; $66 \mathrm{kDa})>98 \%$ were purchased from Sigma-Aldrich. The linear polyethylenimine hydrochloride
(PEI.HCl) $87 \mathrm{kDa}$ polymer was synthesized according to a previous report [23].

\subsection{Expression and purification of the recombinant viral surface protein of SIV (SIVgp120-65 $\mathrm{kDa}$ )}

The recombinant surface viral protein (the envelope gp120, for its apparent molecular weight of $120 \mathrm{kDa}$ ) was expressed in a bacterial host (BL21-DE3 competent cells, ThermoFisher) using a vector ( $\mathrm{pRSET}$; Invitrogen ${ }^{\mathrm{TM}}$ ) containing the coding sequence of the protein. The DNA encoding the SIV gp120 was obtained by PCR amplification with specific primers from the proviral DNA of SIV239. The vector used allows the expression of the protein as fusion with a 6 xHis tag (6xHis-SIVgp120), enabling its purification by immobilized metal affinity chromatography (IMAC) using the HisPurTM Ni NTA purification Kit (ThermoFisher). Upon cloning and selection, the construct was sequenced before induction of protein expression. Several micro-scale tests were performed to determine the best conditions for the expression and purification steps. The correct apparent MW along with the quality of the purified protein was analyzed by SDS-PAGE, stained with Coomassie G-250 SimplyBlue Safe Stain (Invitrogen). After the analysis, the protein that remained dissolved in imidazole buffer after the purification step, was dialyzed twice against distilled water. The UV spectrum of the resulting solution was used to determine the concentration. The molecular mass as well as the theoretical isoelectric point of the protein was calculated from its amino acid sequence using the ProtParam Tools on the ExPASy Server [24]. The predicted molecular mass of the protein resulted in $65 \mathrm{kDa}$ and a theoretical isoelectric point of 8.11 .

\subsection{Instrumental}

The electrochemistry measurements were performed with a home-made microprocessor-controlled electrochemical analyzer with electrochemical impedance spectroscopy module. Experiments were performed in a $10-\mathrm{mL}$ cell with a $7-\mathrm{mm}^{2} \mathrm{GC}$ working electrode (BASinc), a graphite auxiliary electrode and an $\mathrm{Ag} / \mathrm{AgCl} /$ $3 \mathrm{M} \mathrm{KCl}$ reference electrode (BASinc), using 0.100 M HEPES buffer solution brought to $\mathrm{pH}$ 6.5. The NMR experiments were performed at room temperature in a Bruker Ascend-600 spectrometer.

XPS studies were performed on a Physical Electronics spectrometer (PHI Versa Probe II Scanning XPS Microprobe) with scanning monochromatic X-ray Al $\mathrm{K} \alpha$ radiation $(100 \mu \mathrm{m}, 100 \mathrm{~W}$, $20 \mathrm{kV}, 1486.6 \mathrm{eV}$ ) as the excitation source, and a dual beam charge neutralizer. High-resolution spectra were recorded at a given takeoff angle of $45^{\circ}$ by a concentric hemispherical analyzer operating in the constant pass energy mode at $23.5 \mathrm{eV}$, using a $1400 \mu \mathrm{m}$ line (with a $100 \mu \mathrm{m}$ diameter of the $\mathrm{x}$-ray highly focused beam) analysis area. The spectrometer energy scale was calibrated using $\mathrm{Cu} 2 p_{3 / 2}$, $\mathrm{Ag} 3 d_{5 / 2}$, and $\mathrm{Au} 4 f_{7 / 2}$ photoelectron lines at 932.7, 368.2 and $84.0 \mathrm{eV}$, respectively. Under a constant pass energy mode at $23.5 \mathrm{eV}$ condition, the $\mathrm{Au} 4 f_{7 / 2}$ line was recorded with $0.73 \mathrm{eV} F W H M$ at a binding energy (BE) of $84.0 \mathrm{eV}$. PHI Smart Soft-VP 2.6.3.4 software package was used for acquisition and data analysis. A Shirley-type background was subtracted from the signals. Recorded spectra were always fitted using Gauss-Lorentz curves. Atomic concentration percentages of the characteristic elements of the surfaces were determined taking into account the corresponding area sensitivity factor for the different measured spectral regions.

Electron microscopy images were obtained on a Zeiss Supra 40 and Quanta FEG 250 scanning electron microscopes (SEM). Dynamic Light Scattering (DLS) was made with a Zetasizer Nano-Zs, Malvern Instruments, Worcestershire, UK. Visible spectra were obtained with an Evolution Array UV-visible Spectrophotometer 
from Thermo Scientific.

Quartz crystal microbalance (QCM) measurements were made with a Gamry's eQCM $10 \mathrm{M}$ instrument using 6-MHz gold-coated crystals; the series resonant frequency (fs) from Butterworth van Dyke equivalent circuit model was plotted against time. When a deposited film is thin and rigid, the decrease in frequency can be directly correlated to the increase in mass using the Sauerbrey equation [25].

\subsection{Modification of GCE surface and experiment setup}

The 3-mm diameter GCE (BASinc) was polished with $0.3-\mu \mathrm{m}$ alumina powder, rinsed with distilled water and ethanol, and left to dry at room temperature. The PEI-Au solution was made of $1.0 \mathrm{mg}$ of hydrogen tetrachloroaurate(III) trihydrate $\left(\mathrm{HAuCl}_{4} \cdot 3 \mathrm{H}_{2} \mathrm{O}\right)$ and $5.0 \mathrm{mg}$ of $87-\mathrm{kDa}$ linear PEI.HCl in $4.0 \mathrm{~mL}$ of distilled water. The electrochemical cell was prepared with the GCE, an $\mathrm{Ag} / \mathrm{AgCl} / 3 \mathrm{M}$ $\mathrm{KCl}$ reference electrode and a graphite auxiliary electrode immersed in this solution. A constant electrode potential of $-1.2 \mathrm{~V}$ vs $(\mathrm{Ag} / \mathrm{AgCl})$ was applied for an interval of time under stirring. The adequate time of deposition was determined in $45 \mathrm{~s}$. In the absence of PEI. $\mathrm{HCl}$, an $\mathrm{Au}^{0}$ film was electrodeposited on the GC surface after $45 \mathrm{~s}$ of polarization.

Then, GCE/AuNP-PEI was rinsed with distilled water, soaked in $10 \mathrm{~mL}$ of $0.15 \mathrm{M} \mathrm{NH}_{3}$ solution for $10 \mathrm{~min}$ to neutralize the polymeric $-\mathrm{NH}_{2}^{+}-$and $-\mathrm{NH}_{3}^{+}$sites, and left to dry at room temperature. The $-\mathrm{NH}_{2}$ groups of GCE/AuNP-PEI were activated with $5.0 \mu \mathrm{L}$ of $2 \%$ glutaraldehyde (GA) incubated at $4{ }^{\circ} \mathrm{C}$ for $30 \mathrm{~min}$ [10], then washed with distilled water and left to dry in air at room temperature. Finally, the electrode surface was covered with $5.0 \mu \mathrm{L}$ of $2 \mathrm{mg} \mathrm{mL}^{-1}$ protein solution ( $10 \mu \mathrm{g}$ of protein), incubated for $30 \mathrm{~min}$ at room temperature and rinsed with three portions of distilled water.

Two proteins were used to evaluate the efficiency of surface modification: 66-kDa bovine serum albumin (BSA) and $65-\mathrm{kDa}$ recombinant surface protein from SIV (SIVgp120). Each protein was dissolved in distilled water to be dropped on the electrode surface.

The electrochemical characteristics of the modified electrodes and their controls were measured by CV, EIS and SWV, in a conventional electrochemical cell containing the three-electrode arrangement. The electrochemical measurements were performed in 0.100 M HEPES ( $\mathrm{pH} 6.5$ ) containing $5.0 \mathrm{mM} \mathrm{K}_{3}\left[\mathrm{Fe}(\mathrm{CN})_{6}\right] /$ $\mathrm{K}_{4}\left[\mathrm{Fe}(\mathrm{CN})_{6}\right](1: 1)$ mixture. The $\mathrm{pH}$ value was selected close to neutrality considering both the optimal electrochemical response of the redox probe, and the protonation of PEI polymer.

In $\mathrm{CV}$ experiments the electrode potential was varied from -0.2 to $+0.8 \mathrm{~V} \mathrm{vs}(\mathrm{Ag} / \mathrm{AgCl})$, at the scan rate of $50 \mathrm{mV} \mathrm{s}^{-1}$ to monitor the current variation. Square-wave voltammetry (SWV) was carried out at amplitude of $10 \mathrm{mV}$, step potential of $1 \mathrm{mV}$ or $5 \mathrm{mV}$, frequency of $10 \mathrm{~Hz}$, and applied potential difference range from -0.2 to $+0.8 \mathrm{~V} \mathrm{vs}$ $(\mathrm{Ag} / \mathrm{AgCl})$.

Previous to each EIS experiment, the open circuit potential (OCP) was measured. This value was then set as the direct current applied potential difference (DCV) of the EIS measurement, obtaining 30 data points in the frequency range of $50000-0.25 \mathrm{~Hz}$ with $10 \mathrm{mV}$ of alternate current applied potential difference (ACV) amplitude. These last parameters were evaluated in a range to finally select the optimum value for each one. The GCE surface was regenerated by applying $+1.0 \mathrm{~V}$ vs $(\mathrm{Ag} / \mathrm{AgCl})$ in $0.1 \mathrm{M} \mathrm{HCl}$ solution for at least 10 min under stirring, preceded and followed by polishing with $0.3-\mu \mathrm{m}$ alumina powder.

For SEM, visible and XPS spectroscopic characterization, Indium Tin Oxide (ITO films) coated glasses (XOP Glass, XOP Física S.L., Spain) were used as working electrodes. The material (AuNP-PEI) was electrodeposited at $-1.2 \mathrm{~V}$ vs $(\mathrm{Ag} / \mathrm{AgCl})$ for $180 \mathrm{~s}$.
For QCM measurements, the Fil-Tech, QI8010, 6 MHz goldcoated crystals were used; AuNP-PEI was electrodeposited at $-1.2 \mathrm{~V}$ vs $(\mathrm{Ag} / \mathrm{AgCl})$ for $90 \mathrm{~s}$. The modified crystals were washed three times with 5-mL aliquots of distilled water before assembly; then the cell was filled with $5 \mathrm{~mL}$ of distilled water, and later either $\mathrm{NH}_{3}$ or $\mathrm{HCl}$ was added.

\section{Results and discussion}

AuNP were deposited on a conducting surface by application of a reductive potential in the presence of $\mathrm{Au}(\mathrm{III})$ and the polymeric ligand. The visible spectrum of the dark reddish-brown film on the surface of ITO glasses, exhibited a broad absorption band with a maximum at $678 \mathrm{~nm}$ : the surface plasmon resonance band corresponding to gold nanostructures (Fig. S1). In parallel, the yellow $\mathrm{Au}(\mathrm{III})$-PEI solution used for electrodeposition became pink, the typical plasmon resonance band from $\mathrm{Au}^{\circ}$-NPs was observed at $540 \mathrm{~nm}$ together with a zeta-potential value of $+18.5 \pm 2.5 \mathrm{mV}$ and a size distribution of $49.1 \pm 1.0 \mathrm{~nm}$ from dynamic light scattering experiments (Fig. S1). The resonance band was also present in a colloidal solution of $\mathrm{Au}^{\circ}$ stabilized by citrate. In the absence of dissolved PEI.HCl, the reduction of $\mathrm{HAuCl}_{4}$ brought to the deposition of a thin film (from blue to golden, according with the thickness) on the GC or ITO substrate. These results indicated that the positively charged polymeric ligand acted stabilizing the AuNP on the surface and in solution.

The SEM micrographs in Fig. 1 revealed that AuNP-PEI coating was uniformly distributed on the conducting substrate, and the roughness was increased when compared with $\mathrm{Au}^{\circ}$ layer. PEI itself has an adhesion promoting ability on several surfaces, which would assist the deposition [26]. In this context, the coverage resulted affected by PEI chains length: more nuclei were observed on the surface when the linear chain was larger, and the layer topography resulted more homogeneous when the polymer was branched (Fig. S2).

The gold-coated quartz crystals modified with AuNP-PEI were used to evaluate the film response to $\mathrm{pH}$ changes. The addition of $\mathrm{NH}_{3}$ to the aqueous medium in contact with the modified crystal induced a sharp increase of the series resonance frequency $\left(f_{s}\right)$ consistent with mass loss from the thin film due to deprotonation of $-\mathrm{NH}_{2}^{+}-$and $-\mathrm{NH}_{3}^{+}$sites (Fig. S3).

On the other hand, amine groups from PEI chains exposed to distilled water were expected to be mostly protonated. But the addition of $\mathrm{HCl}$ produced a sharp decrease of $f s$, indicating that the mass of the coating increased (Fig. S3). Here, the protonation and solvation of some remaining amine groups on the surface probably induced chain stretching by electrostatic repulsion, exposing hidden $-\mathrm{NH}-$ and $-\mathrm{NH}_{2}$ residues which also accepted $\mathrm{H}^{+}$and became solvated [27].

The basic sites from PEI were protonated even in distilled water or at pH 6.5 of HEPES buffer, so the PEI layer was treated with $\mathrm{NH}_{3}$ to neutralize $\mathrm{H}^{+}$before the activation step. Then, the $-\mathrm{NH}_{2}$ end groups from the chains were converted to the imine link $-\mathrm{N}=\mathrm{C}-$ in the presence of GA reagent, introducing aldehyde groups to bind covalently proteins (Scheme 1). Two biomolecules, with similar molecular weight (MW) and different acid-base properties, were tested: a recombinant 6xHis-SIVgp120 (estimated MW of $65 \mathrm{kDa}$; estimated isoelectric point: 8.11) and BSA (MW: $66 \mathrm{kDa}$; isoelectric point: 4.7). The first one was chosen as a model of antigen to be immobilized on a sensor surface for antibody recognition. BSA is usually selected to cover non-specific binding sites on sensor platforms.

In the assembly step, most of biomolecules interact with PEI, either covalently or by means of electrostatic or weaker forces. But some molecules could diffuse deeper into the polymer layer and 


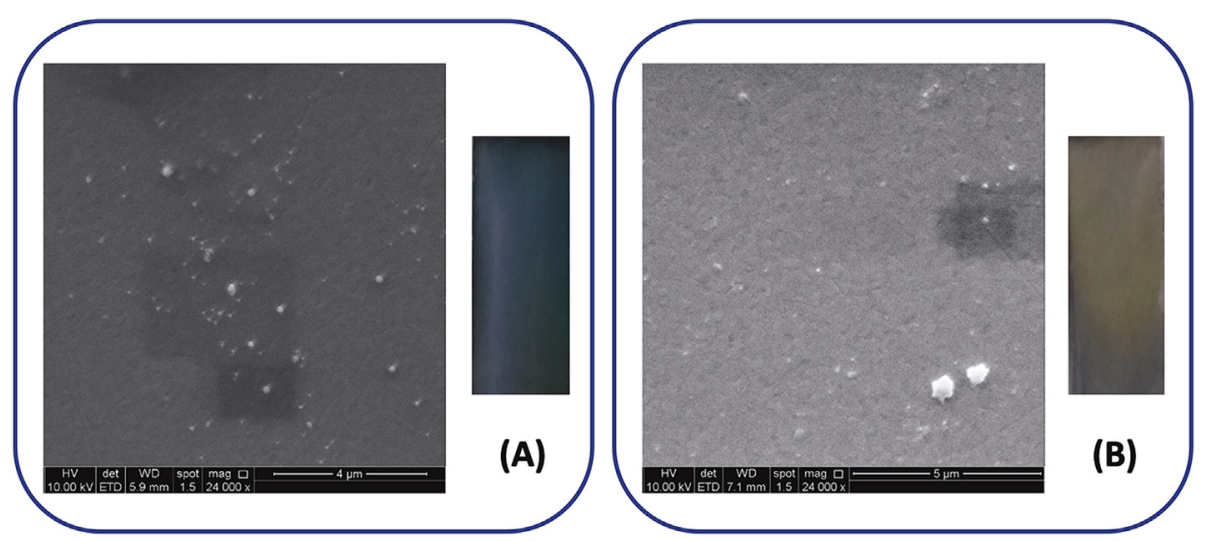

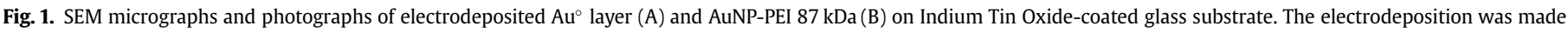
at $-1.2 \mathrm{~V}$ vs $(\mathrm{Ag} / \mathrm{AgCl})$ during $180 \mathrm{~s}$ under convection.

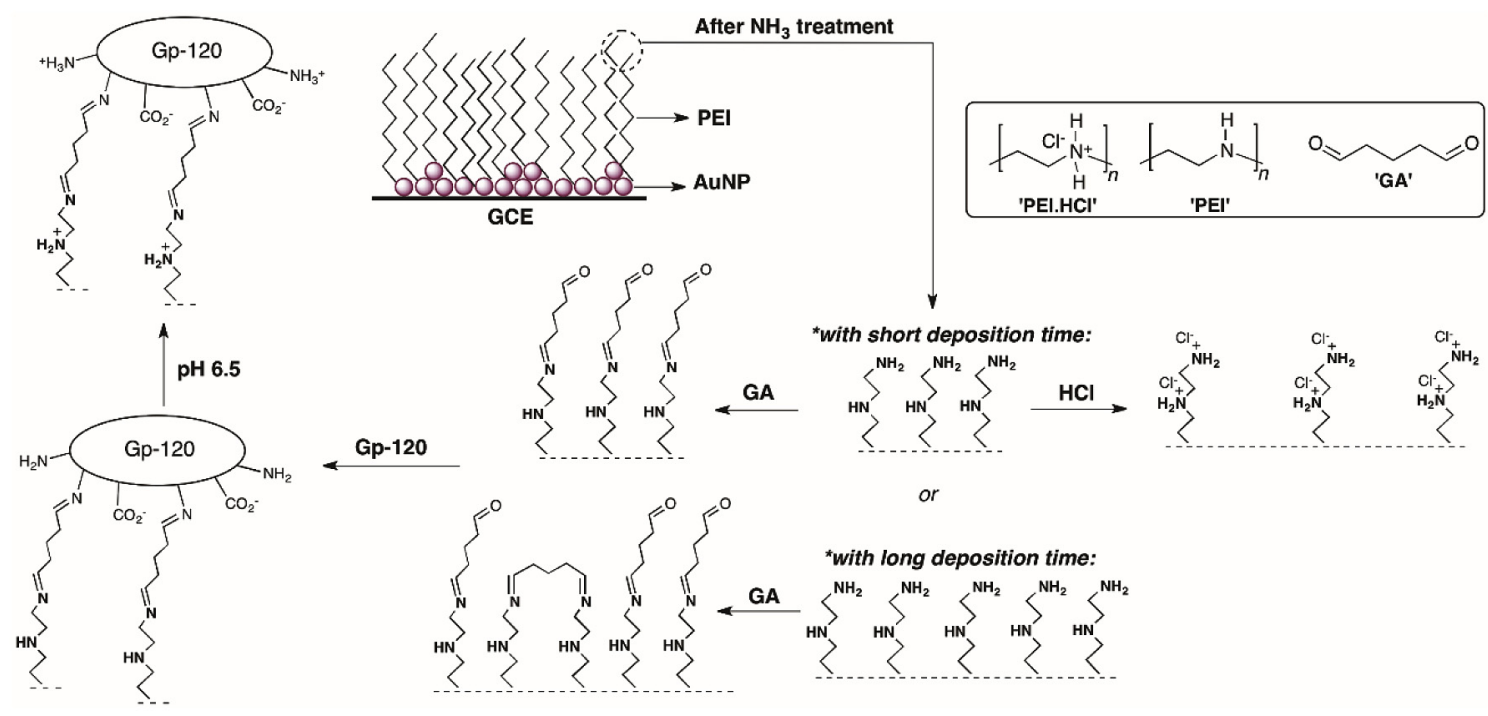

Scheme 1. Chemical modifications performed in the AuNP-PEI system deposited on the GCE surface.

reach the AuNP surface, staying directly adsorbed on it. These interactions in the modifier layer would affect the response of the anionic redox probe $\left(\left[\mathrm{Fe}(\mathrm{CN})_{6}\right]^{3-/ 4-}\right)$ used in electrochemical characterization, altering its diffusion from the bulk solution towards the electrode surface, and eventually the electron transfer kinetics. By this reason, three different electrochemical techniques were used to put in evidence the presence of the proteins in the modifier layer, together with the strength of interaction.

\subsection{XPS and NMR studies}

In order to study the chemical modification performed in the surface of glassy carbon electrodes with PEI and $\mathrm{AuCl}_{4} \mathrm{H}$, ITO films $\left(\mathrm{ITO}_{f}\right)$ were modified in the same way that the GCE. In this way, the surface chemical composition can be easily analyzed by XPS. The results are shown in Fig. 2 and Table 1 . The ITO $_{f}$ present their typical chemical composition related to different indium and tin oxides together with $17.5 \mathrm{wt} \%$ of carbon and some residual copper $(<0.01 \mathrm{wt} \%)$ content as in reported $\mathrm{ITO}_{f}$ [28]. Additionally, the gold content $(22.6 \mathrm{wt} \%)$ was demonstrated when the reduction potential was applied in the presence of $\mathrm{HAuCl}_{4}$ as a consequence of the reduction from $\mathrm{Au}^{3+}$ to $\mathrm{Au}^{0}$ with the concomitant deposition of a

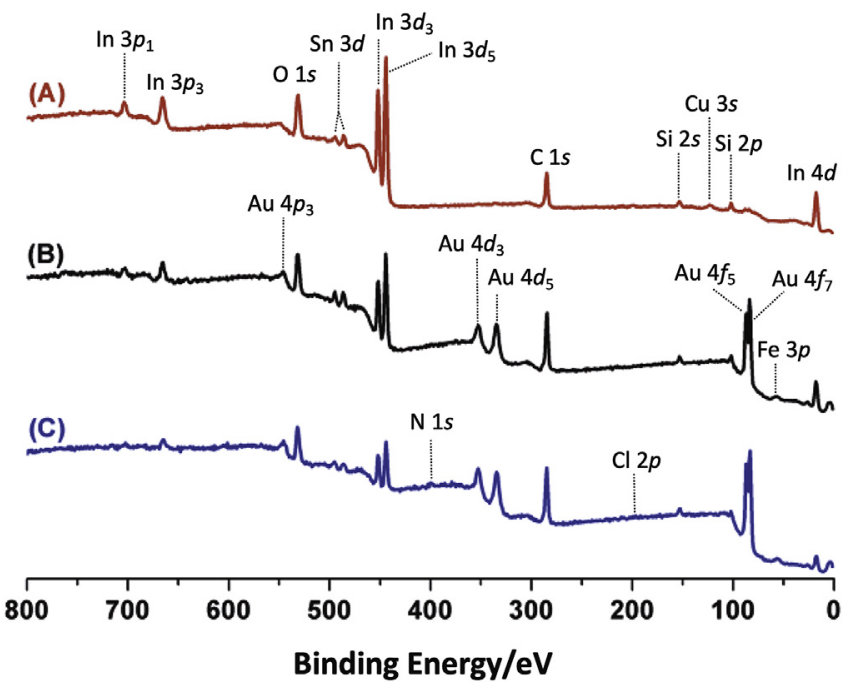

Fig. 2. Panoramic XPS spectra for the $\mathrm{ITO}_{f}(\mathrm{~A}), \mathrm{ITO}_{f}-\mathrm{Au}(\mathrm{B})$ and $\mathrm{ITO}_{f}-\mathrm{Au}-\mathrm{PEI}(\mathrm{C})$ systems. 
Table 1

Atomic composition and elemental analysis ( $\mathrm{wt}_{\%}$ in parentheses) for the indicated samples determined from XPS.

\begin{tabular}{|c|c|c|c|c|c|c|c|c|c|c|}
\hline Sample & $\mathrm{C} 1 \mathrm{~s}$ & $\mathrm{~N} 1 s$ & $01 s$ & Si $2 p$ & $\mathrm{Cl} 2 p$ & Fe $2 p$ & $\mathrm{Cu} 2 p$ & In $3 d$ & Sn $3 d$ & $\mathrm{Au} 4 f$ \\
\hline $\mathrm{ITO}_{f}$ & $46.3(17.5)$ & - & $30.3(15.3)$ & $6.5(5.7)$ & $<0.01$ & - & $<0.01$ & $15.6(56.4)$ & $1.3(5.1)$ & - \\
\hline $\mathrm{ITO}_{f}-\mathrm{Au}$ & $51.5(19.5)$ & - & $14.9(7.5)$ & $21.3(18.8)$ & $<0.01$ & $<0.01$ & - & $7.2(26.1)$ & $1.5(5.4)$ & $3.7(22.6)$ \\
\hline $\mathrm{ITO}_{f}-\mathrm{Au}-\mathrm{PEI}$ & $51.8(25.6)$ & $4.4(2.6)$ & $9.3(6.1)$ & $28.3(32.8)$ & $0.9(1.3)$ & $<0.01$ & - & $2.6(12.4)$ & $0.9(4.3)$ & $1.8(14.9)$ \\
\hline
\end{tabular}

gold surface over the $\mathrm{ITO}_{f}$. The chemical modification of the $\mathrm{ITO}_{f}$ can clearly be observed from the panoramic XPS spectra where the signals corresponding to $\mathrm{Au} 4 f, \mathrm{Au} 4 d$ and $\mathrm{Au} 4 p$ are present and well resolved in comparison with the atomic composition of the unmodified $\mathrm{ITO}_{f}$ (Fig. 2).

The Au $4 f$ XPS spectrum for the $\mathrm{ITO}_{f}$ modified with $\mathrm{AuCl}_{4} \mathrm{H}$ shows Au $4 f_{7 / 2}$ and $\mathrm{Au} 4 f_{5 / 2}$ lines at 83.6 and $87.2 \mathrm{eV}$ with a FWHM of 0.8 corresponding to $\mathrm{Au}^{0}$ [29-31], respectively (Fig. 3). When the $\mathrm{PEI} . \mathrm{HCl}$ polymer was used during the chemical surface modification of the $\mathrm{ITO}_{f}$ a slightly shift and widening of the Au $4 f$ lines to higher binding energies occurred at the same time that the visualization of the $\mathrm{N} 1 s$ signal gave evidences of the immobilization of the polymer structure together with the gold particles. In this sense, the changes of the $\mathrm{Au} 4 \mathrm{f}$ binding energy indicate the interaction between AuNPs and amine groups of the PEI polymer [32]. The N $1 s$ signal presents two components at 398.9 (31\%) and $400.1 \mathrm{eV}$ (69\%) assigned to nonprotonated nitrogen atoms of the PEI polymer as well as to the nitrogen atoms that interact with the gold nanoparticles, respectively $[23,33,34]$. Moreover, the Au $4 f$ XPS spectrum for the ITO $f$-AuPEI films presents two Au $4 f_{7 / 2}$ lines at 84.2 and $85.4 \mathrm{eV}$ corresponding to $\mathrm{Au}^{0}(93 \%)$ and $\mathrm{Au}^{3+}(7 \%)$ species, respectively, which explains the increment in the FWHM of the entire Au $4 f_{7 / 2}$ line. Also, the chloride content can be inferred from the contribution of the PEI.HCl material and not from $\mathrm{HAuCl}_{4}$ since in the $\mathrm{ITO}_{f}$ modified with $\mathrm{Au}^{0}$, the $\mathrm{Cl} 2 p$ signal was undetected. Particularly, the shift and the increment in the FWHM to 1.2 for the $\mathrm{Au}^{0}$ contribution at $84.2 \mathrm{eV}$ was attributed to the chemical interaction of the gold particles with PEI.

In order to explore the interaction between the polymer and the gold particles, solution-state NMR studied were done and the
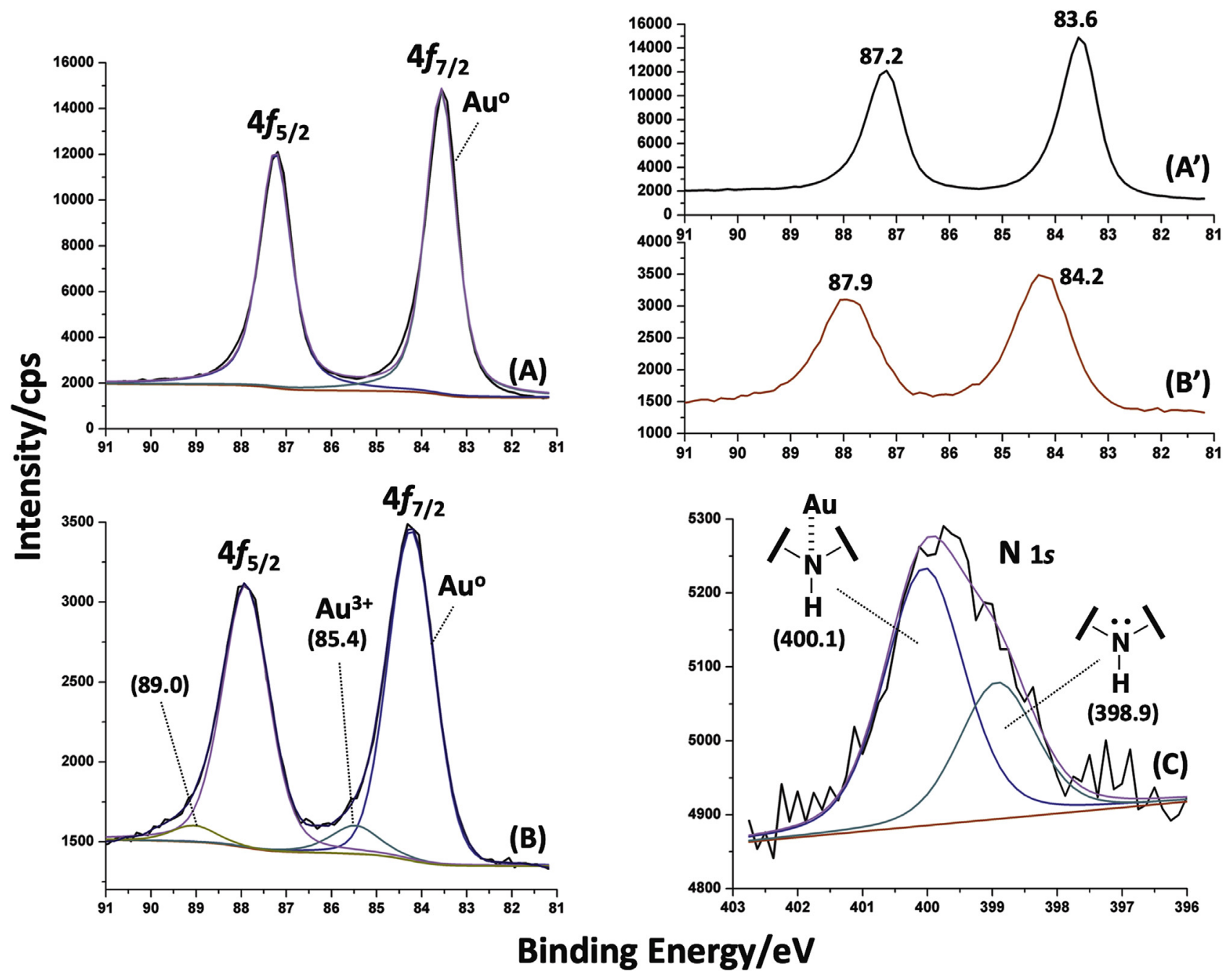

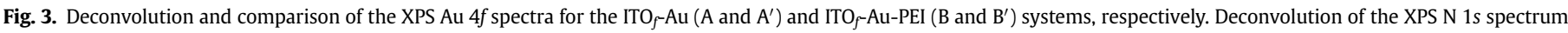
for the $\mathrm{ITO}_{f}$-Au-PEI system (C). 


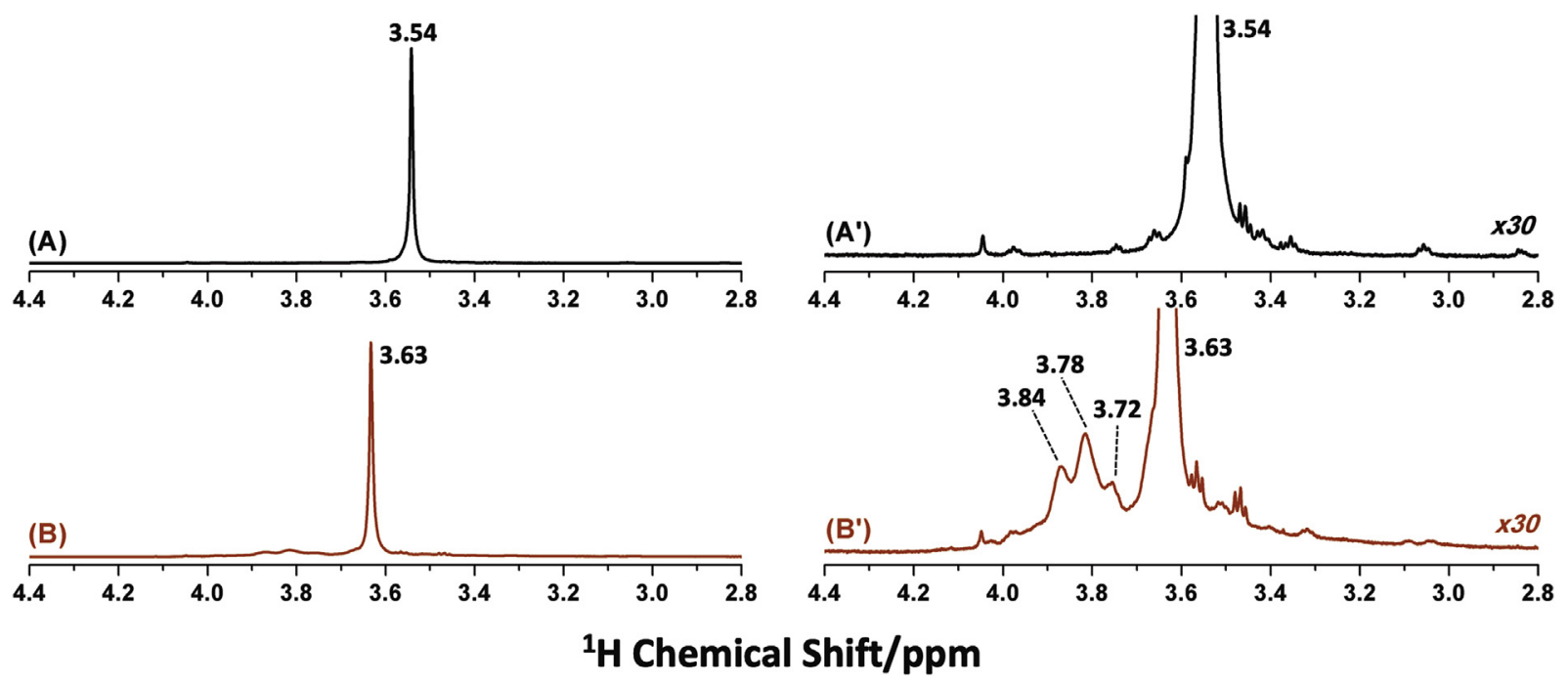

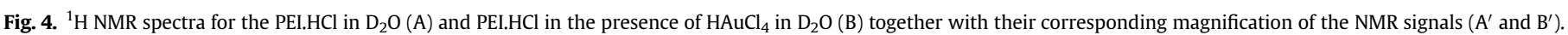

results are shown in Fig. 4. The ethylene segments resonate as a well-defined signal at a proton chemical shift of $3.54 \mathrm{ppm}$ in $\mathrm{D}_{2} \mathrm{O}$, however, the main NMR signal was shifted to $3.63 \mathrm{ppm}$ with the appearance of three new proton signals at 3.72, 3.78 and $3.84 \mathrm{ppm}$ in the presence of $\mathrm{Au}^{3+}$ (which represent a $30 \%$ of area related to the main signal). Also, 2D HSQC NMR spectrum of the $\mathrm{Au}^{3+}$-PEI sample allowed to know that the protons at 3.72/3.84 and $3.78 \mathrm{ppm}$ are bound to the carbons at 50.1 and $61.6 \mathrm{ppm}$ in comparison with the PEI polymer at $43.4 \mathrm{ppm}$. With these results, the $\mathrm{AuCl}_{4}^{-}$ions were partially exchanged with the chloride anions of the protonated amino groups of the polymer material resulting in new proton and carbon resonance signals prior to the formation of $\mathrm{Au}^{0}-\mathrm{PEI}$ nanoparticles, which may also explain the shift in the Au $4 f_{7 / 2}$ line from $83.6 \mathrm{eV}$ in $\mathrm{ITO}_{f}$-Au to $84.2 \mathrm{eV}$ in $\mathrm{ITO}_{f}$-Au-PEI surfaces.

\subsection{Electrochemical characterization of the surface modified with PEI and SIVgp120}

The modification process of the conducting GC surface was characterized by CV, SWV and EIS to record the changes of the electrode behavior before and after each step. The immobilization of AuNP, PEI, GA and the proteins, produced changes in the interfacial charge, capacitance, resistance, mass and thickness at the GC surface, which in turn had a direct effect on the diffusion and/or the electron transfer reaction of the redox probe at the modified surface-electrolyte solution interface.

\subsubsection{Cyclic voltammetry (CV) experiments}

The CV variables $I p, E p$ and $\Delta E p$ obtained with and without the proteins were comparatively analyzed to determine if the attachment of the biomolecules to the modified electrodes could be evidenced by this method (see Comment 1 ).

Cyclic voltammograms and data of the $5 \mathrm{mM}\left[\mathrm{Fe}(\mathrm{CN})_{6}\right]^{3-/ 4-}$ redox probe with different electrodes and the protein SIVgp120 are exhibited in Fig. S4, Table S1 and Table 2. The potential difference of peak-to-peak $(\triangle E p)$ at bare GCE was significantly higher than $\triangle E p$ at any of the modified electrodes [35].

The immobilization of AuNPs with PEI on GCE provided a considerable increase in the anodic (Ipa) and cathodic (Ipc) peak currents from $\left[\mathrm{Fe}(\mathrm{CN})_{6}\right]^{3-/ 4-}$ (by an average of 3.2-fold and of 4.4fold, respectively). However, the presence of GA and/or SIVgp120 could not be distinguished.
On the other hand, $\Delta E p$ resulted more sensitive to detect the attachment of SIVgp120. Comparatively, the GCE/AuNP-PEI-GA assembly (free of protein) exhibited the best condition for probe electron transfer. When SIVgp120 was added to the AuNP-PEI modifier, the $\Delta E p$ values increased $(p<0.01)$, indicating some degree of Au surface passivation determined by the adsorbed protein molecules. The effect on kinetics was even more notorious when the SIVgp120 was covalently attached to the AuNP by means of PEIGA. SIVgp120 adsorption was detected at pH 6.5, even if both PEI and the protein were positively charged (see Comment S2) [36]. In this way, the uptake of SIVgp120 by the modifier layer and the nature of the interaction (covalent binding or adsorption) could be evidenced by $C V$ technique through the variable $\Delta E p$.

\subsubsection{Square-wave voltammetry (SWV) experiments}

The diffusion layer of the probe in SWV is not renewed between SW potential cycles. So, this technique was expected to bring information about the modified GCE surface qualitatively different from the CV approach [21].

Again, both kinetics and diffusion of the probe involved in the electrochemical reaction were improved by surface modification with AuNP-PEI and evidenced by SWV (Fig. S5 and Table S2). The Ip increase after surface modification was over 8 -fold, probably as a consequence of higher electrocatalytic surface area and anion preconcentration (Table 2).

With this technique, the Ep values of GCE/AuNP-PEI-GA and GCE/AuNP-PEI-GA-SIVgp120 (or GCE/AuNP-PEI-SIVgp120) were similar $(p>0.01)$ but the I $p$ values resulted significantly different $(p<0.01)$. These changes in current intensity would be associated to the effects of SIVgp120 on the diffusion layer of the probe.

The electrostatic attraction and other interactions between the $\mathrm{PEIH}^{+}$sites in chains and the anionic redox couple would be more intense in the absence of SIVgp120, because the anionic groups of the protein $\left(-\mathrm{COO}^{-}\right)$could compensate the $\mathrm{PEIH}^{+}$sites in some extent, shielding them from $\left[\mathrm{Fe}(\mathrm{CN})_{6}\right]^{3-/ 4-}$. The AuNP-PEI-GA assembly would reach a higher charge density than AuNP-PEI-GASIVgp120 (where partial shielding had place), acting as better anion preconcentrator (see Comment S3). The consequences were higher $\mathrm{dC}$ values across the diffusion layer and the corresponding increase in Ip response for the probe at GCE/AuNP-PEI-GA (see Comment S4).

The $E p$ value from SWV was not a sensitive variable to detect 
Table 2

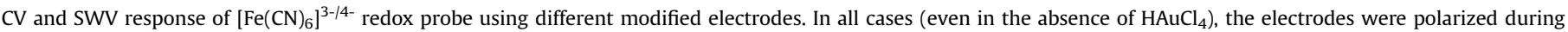
$45 \mathrm{~s}$ at $-1.2 \mathrm{~V}$ vs $(\mathrm{Ag} / \mathrm{AgCl})$ for preparation. Six replicates were made in each case.

\begin{tabular}{|c|c|c|c|}
\hline Electrode & $\Delta E p(\mathrm{CV})$ and $E p(\mathrm{SWV})$ vs $(\mathrm{Ag} / \mathrm{AgCl}) / \mathrm{mV}$ & $I p(\mathrm{SWV}) / \mu \mathrm{A}$ & Normalized $I p$ \\
\hline GCE & $343 \pm 16$ and $404 \pm 101$ & $2.9 \pm 0.9$ & 0.09 \\
\hline GCE/AuNP-PEI-GA & $112 \pm 3$ and $208 \pm 2$ & $33 \pm 4$ & 1.00 \\
\hline GCE/AuNP-PEI-GA-SIVgp 120 & $142 \pm 5$ and $206 \pm 6$ & $24 \pm 1$ & 0.72 \\
\hline GCE/AuNP-PEI-SIVgp 120 & $134 \pm 4$ and $210 \pm 3$ & $25 \pm 2$ & 0.75 \\
\hline GCE/AuNP-PEI-GA-SIVgp120a & $114 \pm 4$ and $266 \pm 100$ & $31 \pm 3$ & 0.94 \\
\hline
\end{tabular}

a The step of reaction with GA was made at room temperature instead of $5^{\circ} \mathrm{C}$.

differences arising from the attachment of SIVgp120 to GA or PEI ( $p>0.01$ ), whereas the $\Delta E p$ obtained from CV gave evidence of the nature of protein binding (see Comment S5). The PEI chains (MW: $87 \mathrm{kDa}$ ) would be acting as spacer between SIVgp120 and AuNP, under the SW pulsed perturbation. This barrier combined with the SW potential pulse would prevent the electrode from fouling by the protein (see Comment S6).

\subsubsection{Electrochemical impedance spectroscopy (EIS) experiments}

EIS is an effective method to evaluate the interfacial properties of the modified conducting surfaces [37]. The pinhole degree and the thickness of the organic layer on the surface determine the permeability and electron transfer of the redox probe [15]. In EIS, the electron transfer reaction of $5 \mathrm{mM}\left[\mathrm{Fe}(\mathrm{CN})_{6}\right]^{3-/ 4-}$ at the electrode interface was the rate-determining step at the bare GCE (Fig. S6).

Upon surface modification with AuNP-PEI platform, the experimental data fitted well to the Randles' equivalent circuit model (Fig. S6), indicating a mixed electron transfer and diffusion control mechanism for the $\left[\mathrm{Fe}(\mathrm{CN})_{6}\right]^{3-/ 4-}$ reaction. The modification with gold nanoparticles enhanced the rate of electron transfer for the redox probe, which was evidenced by the dramatic decrease of the charge transfer resistance $\left(R_{c t}\right)$ after AuNP-PEI electrodeposition step [13].

About the layers with protein, the low $R_{c t}$ values (Table 3 ) indicated that the GCE/AuNP-PEI-GA-SIVgp120 system was not passivated by SIVgp120, since PEI acted as spacer under this kind of pulsed perturbation. In the particular case of $R_{c t}$ from GCE/AuNPPEI-SIVgp120, the absence of the bifunctional GA caused a poor retention of the protein by PEI, which reached the AuNP surface in some extent and adsorbed on it, slowing the electron transfer rate of the probe.

The equivalent circuit for the modified cells under study did not include a pure capacitor, because this element did not behave ideally in these systems. Instead, a constant phase element (CPE) was included, which incorporates the Helmholtz double layer and surface roughness or heterogeneity of the electrode.

The impedance $(Z)$ of a $C P E$ has the form:
$Z_{C P E}=Q^{-1}(j \omega)^{-\alpha}$

$Q$ becomes equal to capacitance when $\alpha$ is 1 . For a CPE, the exponent is less than one [37]. In the systems under study, the bare GCE behaved almost ideally ( $\alpha$ close to 1 ), at the time that $Q$ was the smallest in the absence of nanoparticles. Both GCE/AuNP-PEI-GASIVgp120 and GCE/AuNP-PEI-SIVgp120, in which the protein was present, behaved as electrochemical capacitors and were described as $C P E$ with parameters of similar value. In the case of GCE/AuNPPEI-GA, the estimated capacitance (reflecting the density of bound anions from the buffer and probe) was higher because there was no shielding of the positive sites on PEI by proteins.

The $\left[\mathrm{Fe}(\mathrm{CN})_{6}\right]^{3-/ 4-}$ diffusion mass transport under alternating applied potential difference was influenced by the presence of SIVgp120 (either covalently bound or not) on the AuNP-PEI substrate. The Warburg diffusion coefficient $\left(A_{w}\right)$ adopted similar values in these cases with SIVgp120, but increased a 25\% when GA was the last compound of the modifier layer. In GCE/AuNP-PEI-GA assembly, the positive charge density on PEI chains was higher, probably inhibiting the $\left[\mathrm{Fe}(\mathrm{CN})_{6}\right]^{3-/ 4-}$ diffusion under the small amplitude sinusoidal perturbation.

\subsection{Effect of the AuNP deposition time}

The electro-deposition time of AuNP was increased from $45 \mathrm{~s}$ to $180 \mathrm{~s}$ in order to fill in the film on GCE. The relevance of the density of AuNP-PEI layer could be analyzed by comparing the responses of the probe at GCE/AuNP-PEI-GA with different deposition times. The $\mathrm{CV}$ experiments showed an increase of Ip values with longer times, being consistent with a higher electroactive surface area and the more efficient preconcentration of the redox couple (Fig. 5). The $\Delta E p$ also presented an increase, probably associated to fouling arising from higher amounts of PEI. The chains of the positively charged polymer bound to AuNP should be extended as a consequence of the electrostatic repulsion, but if the density of molecules were high, some of them could be partially adsorbed on Au surface. This effect was also observed in SWV experiments: the Ep shifted towards higher values on filling the GCE surface with NP and

Table 3

Estimated parameters from impedance spectra of Fig. S6, and standard error \% (SE\%) using the Randles' model for equivalent circuit. Redox probe: $[\text { Fe(CN) }]^{3-/ 4-}$.

\begin{tabular}{|c|c|c|c|c|}
\hline Estimated Parameter & GCE/AuNP-PEI-GA-SIVgp120 & GCE/AuNP-PEI-GA & GCE/AuNP-PEI-SIVgp120 & GCE \\
\hline$R_{c t} / \mathrm{ohm}$ & $\begin{array}{l}425 \\
\text { (SE\%: 23) }\end{array}$ & $\begin{array}{l}413 \\
\text { (SE\%: 3.5) }\end{array}$ & $\begin{array}{l}935 \\
\text { (SE\%: 6.3) }\end{array}$ & $\begin{array}{l}1.82 \times 10^{5} \\
(\mathrm{SE} \%: 4.0)\end{array}$ \\
\hline$A_{w} / \mathrm{ohm} \mathrm{s}^{-1 / 2}$ & $\begin{array}{l}3319 \\
(\mathrm{SE} \%: 8.5)\end{array}$ & $\begin{array}{l}4178 \\
\text { (SE\%: 1.1) }\end{array}$ & $\begin{array}{l}3341 \\
\text { (SE\%: } 3.4)\end{array}$ & - \\
\hline$Q / \mu F$ & $\begin{array}{l}5.19 \\
\text { (SE\%: 13) }\end{array}$ & $\begin{array}{l}57.3 \\
\text { (SE\%: 2.6) }\end{array}$ & $\begin{array}{l}4.75 \\
\text { (SE\%: 5.9) }\end{array}$ & $\begin{array}{l}0.240 \\
\text { (SE\%: } 2.3 \%)\end{array}$ \\
\hline$\alpha$ & $\begin{array}{l}0.699 \\
\text { (SE\%: 2.9) }\end{array}$ & $\begin{array}{l}0.427 \\
(\mathrm{SE} \%: 0.8)\end{array}$ & $\begin{array}{l}0.700 \\
\text { (SE\%: 1.3) }\end{array}$ & $\begin{array}{l}0.906 \\
(\mathrm{SE} \%: 0.50)\end{array}$ \\
\hline
\end{tabular}




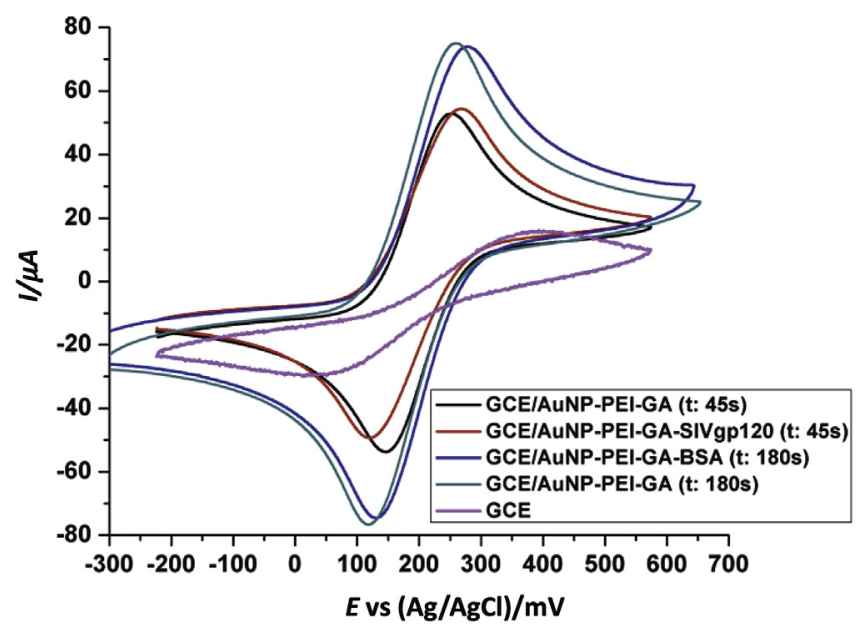

Fig. 5. Cyclic voltammograms obtained for a $5 \mathrm{mM}\left[\mathrm{Fe}(\mathrm{CN})_{6}\right]^{3-/ 4-}$ solution in $0.100 \mathrm{M}$ HEPES buffer, pH 6.5, using GCE and other modified electrodes interacting with proteins. The electrodeposition time is indicated in the legend in parentheses. Rate scan: $50 \mathrm{mV} \mathrm{s}^{-1}$.

polymer (Fig. 6).

An outstanding difference between the CV and SWV results is that Ip value was no significantly altered using the pulsed technique. Meanwhile CV voltammograms showed marked increase of I $p$ values with the denser modifier. Further research should be done to clarify this difference [21].

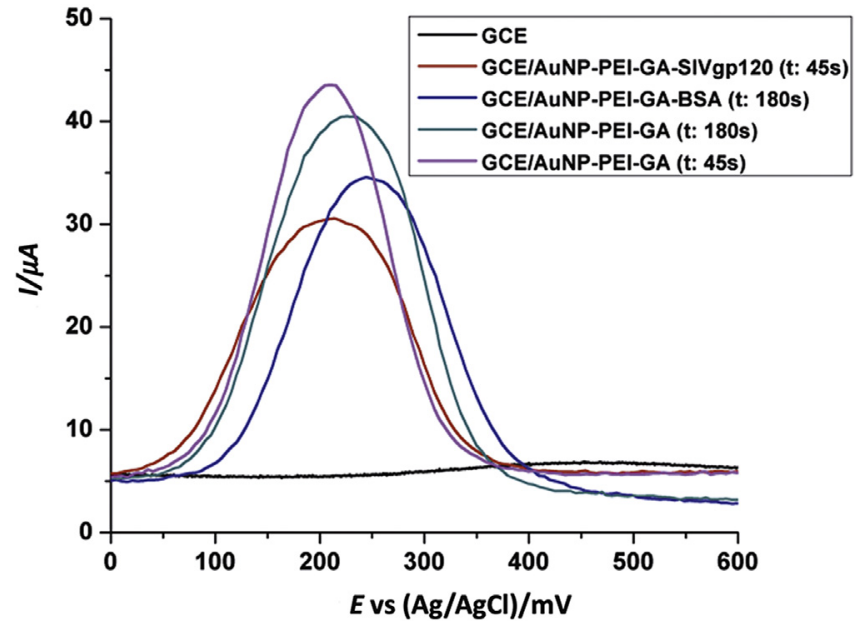

Fig. 6. Square-wave voltammograms obtained for a $5 \mathrm{mM}\left[\mathrm{Fe}(\mathrm{CN})_{6}\right]^{3-/ 4-}$ solution in 0.100 M HEPES buffer, pH 6.5, using GCE and other modified electrodes interacting with proteins. The electrodeposition time is indicated in parentheses. Experimental conditions: step: $5 \mathrm{mV}$, frequency: $10 \mathrm{~Hz}$, amplitude: $10 \mathrm{mV}$.
About EIS experiments presented in Figs. S6 and S7, the capacitance $Q$ increased with deposition time, most likely due to the evolution of the surface morphology. Aw underwent a significant decrease at longer deposition times, meaning that the resistance to diffusion was lower and the rate control had a lower contribution from mass transport (Tables 3 and 4). Again, the abundance of PEI molecules might have induced the stretching of the positive chains of polymer due to electrostatic repulsion, facilitating the transport of $\left[\mathrm{Fe}(\mathrm{CN})_{6}\right]^{3-/ 4-}$ through the insulating layer under this conformation (Scheme 1).

\subsection{Electrochemical characterization of the surface modified with PEI and BSA}

Then, BSA was selected as model protein, and was covalently attached to the modifier layer obtained with the longest electrodeposition time. The CV studies indicated that $\Delta E p$, Ipa and Ipc were not sensitive variables to detect kinetic or diffusion changes with the redox probe upon BSA covalent attachment (Fig. S8; see Comment S7). But making an overall analysis, these Ipa and Ipc values resulted significantly enhanced by the denser layer when compared with the response using AuNP-PEI-GA-SIVgp120 layer. This appears as an evidence of the probe preconcentration effect and the importance of the density of positive sites on polymer chains (Fig. 5).

SWV studies gave more significant information about changes in the AuNP-PEI-GA environment upon BSA uptake (Fig. S9). Ip $(p<0.01)$ and $E p(p<0.05)$ values indicated that the presence of BSA in the modifier layer affected both diffusion and (in lower extent) the kinetics of $\left[\mathrm{Fe}(\mathrm{CN})_{6}\right]^{3-/ 4-}$ redox probe, making a difference with the basic SIVgp120 molecule (Table 5). The Ep values for redox probe were higher in the experiments with AuNP-PEI-GA(BSA), when compared with the BSA adsorbed on AuNP-PEI; the bifunctional GA could have brought some degree of surface passivation.

The probe diffusion in the insulating layer was dependent on $\mathrm{dC} / \mathrm{dx}$, and $\mathrm{C}^{\prime}$ was expected to be lower in the presence of BSA, as was Ip. The Ip value resulted especially lower in the case of noncovalent interaction (AuNP-PEI-BSA), where the negatively charged BSA seemed to strongly affect the probe preconcentration efficiency of the layer.

On the other hand, the covalent binding of BSA did not produce a marked change of Ip. A possible explanation could be a low efficiency of the reaction between PEI-GA and BSA. In this dense modifier, GA could have been acted as crosslinker of neighbor PEI chains, leaving a relatively low quantity of aldehyde groups from chains available for the reaction with BSA.

These results indicated that $E p$ and Ip values from SWV were sensitive to GA reaction and to the presence of BSA, distinguishing the nature of the interaction. In an overall picture, SW voltammograms did not evidence the preconcentration efficiency as function of the density of positive sites in the layer (Fig. 6). Instead, this type

Table 4

Estimated parameters from impedance spectra of Fig. S7 and standard error \% (SE\%) using the Randles model for equivalent circuit. Redox probe: $[\text { Fe(CN) }]^{3-/ 4-}$.

\begin{tabular}{|c|c|c|c|c|}
\hline & GCE/AuNP-PEI-GA-BSA & GCE/AuNP-PEI-GA & GCE/AuNP-PEI-BSA 0 min in buffer & GCE/AuNP-PEI-BSA $30 \mathrm{~min}$ in buffer \\
\hline$R_{c t} / \mathrm{ohm}$ & $\begin{array}{l}472 \\
\text { (SE\%: 4.1) }\end{array}$ & $\begin{array}{l}388 \\
(\mathrm{SE} \%: 26)\end{array}$ & $\begin{array}{l}2774 \\
\text { (SE\%: 2.6) }\end{array}$ & $\begin{array}{l}10548 \\
(\mathrm{SE} \%: 2.5)\end{array}$ \\
\hline$A_{w} / \mathrm{ohm} \mathrm{s}^{-1 / 2}$ & $\begin{array}{l}2346 \\
\text { (SE\%: 11) }\end{array}$ & $\begin{array}{l}2578 \\
\text { (SE\%: 15) }\end{array}$ & $\begin{array}{l}3226 \\
\text { (SE\%: 5.1) }\end{array}$ & $\begin{array}{l}3748 \\
\text { (SE\%: 14) }\end{array}$ \\
\hline$Q / \mu \mathrm{F}$ & $\begin{array}{l}12.1 \\
\text { (SE\%: 10) }\end{array}$ & $\begin{array}{l}136 \\
\text { (SE\%: 4.9) }\end{array}$ & $\begin{array}{l}1.85 \\
\text { (SE\%: } 5.2 \text { ) }\end{array}$ & $\begin{array}{l}0.998 \\
\text { (SE\%: 3.6\%) }\end{array}$ \\
\hline$\alpha$ & $\begin{array}{l}0.592 \\
\text { (SE\%: 3.0) }\end{array}$ & $\begin{array}{l}0.409 \\
\text { (SE\%: 3.5) }\end{array}$ & $\begin{array}{l}0.784 \\
\text { (SE\%: } 0.87)\end{array}$ & $\begin{array}{l}0.843 \\
(\mathrm{SE} \%: 0.60)\end{array}$ \\
\hline
\end{tabular}


Table 5

$\mathrm{CV}$ and SWV responses of $\left[\mathrm{Fe}(\mathrm{CN})_{6}\right]^{3-/ 4-}$ redox probe using different modified electrodes.

\begin{tabular}{|c|c|c|c|c|c|}
\hline \multirow[t]{2}{*}{ Electrode } & \multicolumn{3}{|l|}{$C V$} & \multicolumn{2}{|l|}{ SWV } \\
\hline & $\Delta E p / \mathrm{mV}$ & 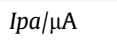 & $I p c / \mu \mathrm{A}$ & Ep vs $(\mathrm{Ag} / \mathrm{AgCl}) / \mathrm{mV}$ & $I p / \mu \mathrm{A}$ \\
\hline GCE & $343 \pm 16$ & $17 \pm 3$ & $12 \pm 1$ & $404 \pm 101$ & $2.9 \pm 0.9$ \\
\hline GCE/AuNP-PEI-GA & $141 \pm 2$ & $93 \pm 3$ & $98 \pm 3$ & $226 \pm 8$ & $35.6 \pm 0.7$ \\
\hline GCE/AuNP-PEI-GA-BSA & $145 \pm 6$ & $91 . \overline{7} \pm 0.2$ & $100.0 \pm 0.4$ & $241 \pm 3$ & $30.57 \pm 0.07$ \\
\hline GCE/AuNP-PEI-BSA & $181 \pm 2$ & $52.4 \pm 0.2$ & $42.8 \pm 0.3$ & $210 \pm 10$ & $14.7 \pm 0.7$ \\
\hline
\end{tabular}

of perturbation put in evidence the presence of the proteins by the shielding effect, and the penetration by fouling of the NP surface.

In EIS experiments, the presence of BSA affected the kinetics of the probe and then $R_{c t}$ values, especially when the protein was directly adsorbed on AuNP-PEI layer. This non-covalent interaction of BSA also produced diffusion constrains to the probe (Fig. S7 and Table 4).

The departure from a pure capacitor behavior was more evident in the GCE/AuNP-PEI-GA system, getting closer to the electronic behavior upon BSA addition, just as in the case of SIVgp120 interaction.

The increase of $Q$ in the GCE/AuNP-PEI-GA system vs GCE was clearly due to a higher density of $\mathrm{PEIH}^{+}$in the insulating layer. But $Q$ dramatically decreased in the presence of adsorbed BSA, a negatively charged globular biomolecule capable of penetrating the dielectric layer and exchanging anions with the $\mathrm{PEIH}^{+}$sites of the expanded chains.

\subsection{BSA desorption in buffer HEPES}

The GCE/AuNP-PEI was put in contact with BSA solution, and then the electrochemical response of the modified electrode was tested to determinate if BSA had been uptaken. The decrease of $I p$ for GCE/AuNP-PEI-BSA when compared with GCE/AuNP-PEI-GA was a strong evidence of BSA interaction.

BSA from the aqueous solution could interact with $\mathrm{PEIH}^{+}$by means of the ionized groups. In this case, the counter anion chloride had to be exchanged by the $-\mathrm{COO}^{-}$of the protein, which was the only solute in that medium. Later, the GCE/AuNP-PEI-BSA was put in contact with HEPES buffer, and the reversible exchange reaction could take place releasing BSA. Some of the free protein molecules must have diffused inside the layer towards the AuNP, and stayed attached to the surface. As a consequence, two overlapping peaks could be detected by SWV using a potential step of $5 \mathrm{mV}$. The peak at $430 \mathrm{mV}$ vs $(\mathrm{Ag} / \mathrm{AgCl})$ would correspond to the probe sensing the situation of BSA adsorbed to the conductive interface (AuNP in this case), and the peak at $220 \mathrm{mV}$ would indicate the presence of some regions on the AuNP surface free of BSA, or even the fraction of BSA still interacting with PEI in the dielectric layer (Fig. S10).

EIS results were consistent with the permeation of BSA and fouling of the AuNP surface (high $R_{c t}$ ), also slowing down the mass transport of the probe (high $A w$ ). The protein released from the PEI chains would form a dielectric barrier on the nanoparticles which had features of a pure electrical capacitor ( $\alpha$ closer to 1 ) (Fig. S11 and Table 4).

\section{Conclusions}

AuNP decorated with PEI were successfully electrodeposited on conductive surfaces. The detection of the plasmonic resonance broad band indicated that the gold film was nanostructured in the presence of the linear polymer with $49 \mathrm{~nm}$-size nanostructures.
The electrostatic interaction between $\mathrm{AuCl}_{4}^{-}$and $\mathrm{PEIH}^{+}$evidenced by solution-state NMR, contributed to the electrodeposition of AuNP instead of an $\mathrm{Au}^{\circ}$ continuous surface. This difference was also observed in the photographs. XPS spectra evidenced the immobilization of the polymer on AuNP, and QCM results exhibited the polymer response to $\mathrm{pH}$ changes. SEM micrographs showed changes in surface topology caused by polymer chain length.

The most relevant experimental variables of three electrochemical techniques to evidence surface interactions were investigated. The redox probe activity monitored by SWV and CV put in evidence the surface changes after each modification step. The preconcentration of the probe and the increase of electrode surface area were evidenced by comparing the responses at GCE/AuNP-PEIGA with different deposition times. The CV experiments showed an increase of Ip values with longer times, which was not evident with SWV.

Instead, SW experiments put in evidence the presence of the proteins. The adsorption of SIVgp120 or BSA on GCE/AuNP-PEI induced a marked decrease of Ip values, probably due to the shielding effect of the biomolecules on the positively charged polymer. It was more notorious with negatively charged BSA on the denser polymeric layer. The covalent binding of the proteins produced the same effect on the diffusion of the probe.

With SWV, we could infer that the protein in the modifier was spaced by PEI from the electrode interface, especially in the case of positively charged SIVgp120. However, BSA reached the NP surface, inducing some degree of fouling.

With EIS methodology, four parameters estimated from Randles' equivalent circuit gave enough information to evidence the protein binding and the nature of this interaction. Clearly, the modifiers with SIVgp120 had similar $A w, Q$ and $\alpha$ values, but the $R_{C t}$ was significantly higher when the protein was just adsorbed on AuNP-PEI indicating some degree of fouling. The absence of protein was characterized by higher capacitance $(Q)$ and a significant departure from the ideal element, together with higher $A w$ due to diffusion constrains under small sinusoidal perturbations.

The CGE/AuNP-PEI-GA system with higher amount of AuNP-PEI presented less diffusion constrain and higher $Q$ values. The high density of positive sites could induce chain expansion by means of repulsive electrostatic forces, facilitating the mass transport of the probe towards the NP surface. The capacitance was significantly affected by the adsorption of negatively charged BSA, which could penetrate the dielectric layer and reach the NP surface. Chloride counter ions of $\mathrm{PEIH}^{+}$sites might have been exchanged by $-\mathrm{COO}^{-}$ from BSA, and the interaction of the polymer with the anionic probe resulted inhibited by this biomolecule. The covalent binding of BSA to GCE/AuNP-PEI-GA could be evidenced by a decrease in $Q$ value.

The desorption of BSA from the modifier dielectric layer could be monitored by SWV and by EIS. Those biomolecules electrostatically retained in the layer were exchanged by the anion of the HEPES buffer, and diffused in all directions. Some of them reached the NP conductive surface and adsorbed on it, inhibiting the 
electron transfer of the probe.

\section{Acknowledgments}

The authors gratefully acknowledge the financial support from Universidad de Buenos Aires (UBACyT 2017-2019/22BA), CONICET (PIP 14-16/130, PIP 14-16/255 and PIP 14-16/029), ANPCyT (PICT 2016-1723) and UNPSJB (PI 1236, 10/C319). J.M.L.M. thanks Universidad de Málaga (Spain) for his researcher fellowship. A.J.B thanks UBA for his student fellowship. The authors thank Dr. M.E. Villanueva and Dr. G.J. Copello for the access to QCM.

\section{Appendix A. Supplementary data}

Supplementary data to this article can be found online at https://doi.org/10.1016/j.electacta.2019.01.154.

\section{References}

[1] S. Yan, S. Zhang, Y. Lin, G. Liu, Electrocatalytic performance of gold nanoparticles supported on activated carbon for methanol oxidation in alkaline solution, J. Phys, Chem. C 115 (2011) 6986-6993.

[2] M. Stratakis, H. Garcia, Catalysis by supported gold nanoparticles: beyond aerobic oxidative processes, Chem. Rev. 112 (2012) 4469-4506.

[3] R. Viswambari Devi, M. Doble, R.S. Verma, Nanomaterials for early detection of cancer biomarker with special emphasis on gold nanoparticles in immunoassays/sensors, Biosens. Bioelectron. 68 (2015) 688-698.

[4] A. Wong, C.A. Razzino, T.A. Silva, O. Fatibello-Filho, Square-wave voltammetric determination of clindamycin using a glassy carbon electrode modified with graphene oxide and gold nanoparticles within a crosslinked chitosan film, Sensor. Actuator. B Chem. 231 (2016) 183-193.

[5] E.A. Khudaish, F. Al-Nofli, J.A. Rather, M. Al-Hinaai, K. Laxman, H.H. Kyaw, S. Al-Harthy, Sensitive and selective dopamine sensor based on novel conjugated polymer decorated with gold nanoparticles, J. Electroanal. Chem. 761 (2016) 80-88.

[6] V.P. Torchilin, T.S. Levchenko, K.R. Whiteman, A.A. Yaroslavov, A.M. Tsatsakis, A.K. Rizos, E.V. Michailova, M.I. Shtilman, Amphiphilic poly-Nvinylpyrrolidones: synthesis, properties and liposome surface modification, Biomaterials 22 (2001) 3035-3044.

[7] Y.Z. Tan, D. Wu, H.T. Lee, H. Wang, A. Honciuc, J.W. Chew, Synthesis of ligandcarrying polymeric nanoparticles for use in extraction and recovery of meta ions, Colloids Surf. A Physicochem. Eng. Asp. 533 (2017) 179-186.

[8] P. Zhang, B. Li, J. Du, Y. Wang, Regulation the morphology of cationized gold nanoparticles for effective gene delivery, Colloids Surfaces B Biointerfaces 157 (2017) 18-25.

[9] H. Veisi, S. Najafi, S. Hemmati, Pd(II)/Pd(0) anchored to magnetic nanoparticles (Fe304) modified with biguanidine-chitosan polymer as a novel nanocatalyst for Suzuki-Miyaura coupling reactions, Int. J. Biol. Macromol. 113 (2018) 186-194.

[10] A. Güner, E. Cevik, M. Senel, L. Alpsoy, An electrochemical immunosensor for sensitive detection of Escherichia coli 0157:H7 by using chitosan, MWCNT, polypyrrole with gold nanoparticles hybrid sensing platform, Food Chem. 229 (2017) 358-365.

[11] T.R. Silva, D. Brondani, E. Zapp, I. Cruz Vieira, Electrochemical sensor based on gold nanoparticles stabilized in poly(allylamine hydrochloride) for determination of vanillin, Electroanalysis 27 (2015) 465-472.

[12] S. Zhang, N. Huang, O. Lu, M. Liu, H. Li, Y. Zhang, S. Yao, A double signal electrochemical human immunoglobulin G immunosensor based on gold nanoparticles-polydopamine functionalized reduced graphene oxide as a sensor platform and AgNPs/carbon nanocomposite as signal probe and catalytic substrate, Biosens. Bioelectron. 77 (2016) 1078-1085.

[13] J. Wu, J. He, Y. Zhang, Y. Zhao, Y. Niu, C. Yu, Reusable voltammetric immunosensor for SCD40L, a biomarker for the acute coronary syndrome, using a glassy carbon electrode modified with a nanocomposite consisting of gold nanoparticles, branched polyethylenimine and carboxylated multiwalled carbon nanot, Microchim. Acta 184 (2017) 1837-1845.

[14] A. Afkhami, P. Hashemi, H. Bagheri, J. Salimian, A. Ahmadi, T. Madrakian, Impedimetric immunosensor for the label-free and direct detection of botulinum neurotoxin serotype A using Au nanoparticles/graphene-chitosan composite, Biosens. Bioelectron. 93 (2017) 124-131.
[15] C.-H. Lin, M.-J. Lin, C.-C. Wu, Effect of the chain length of a modified layer and surface roughness of an electrode on impedimetric immunosensors, Anal. Sci. 33 (2017) 327-333.

[16] S. Xu, R. Zhang, W. Zhao, Y. Zhu, W. Wei, X. Liu, J. Luo, Self-assembled polymeric nanoparticles film stabilizing gold nanoparticles as a versatile platform for ultrasensitive detection of carcino-embryonic antigen, Biosens. Bioelectron. 92 (2017) 570-576

[17] Y. Li, Y. Chen, D. Deng, L. Luo, H. He, Z. Wang, Water-dispersible graphene/ amphiphilic pyrene derivative nanocomposite: high AuNPs loading capacity for CEA electrochemical immunosensing, Sensor. Actuator. B Chem. 248 (2017) 966-972.

[18] C. Sun, L. Ma, Q. Qian, S. Parmar, W. Zhao, B. Zhao, J. Shen, A chitosan-Auhyperbranched polyester nanoparticles-based antifouling immunosensor for sensitive detection of carcinoembryonic antigen, Analyst 139 (2014) 4216-4222.

[19] Y. Niu, T. Yang, S. Ma, F. Peng, M. Yi, M. Wan, C. Mao, Biosensors and Bioelectronics Label-free immunosensor based on hyperbranched polyester for speci fi c detection of $\alpha$-fetoprotein, Biosens. Bioelectron. 92 (2017) $1-7$.

[20] J. Lazar, C. Schnelting, E. Slavcheva, U. Schnakenberg, Hampering of the stability of gold electrodes by ferri-/ferrocyanide redox couple electrolytes during electrochemical impedance spectroscopy, Anal. Chem. 88 (2016) $682-687$.

[21] S. Lambot, E.C. Slob, I. Den Van Bosch, B. Stockbroeckx, M. Vanclooster, Modeling of ground-penetrating radar for accurate characterization of subsurface electric properties, IEEE Trans. Geosci. Rem. Sens. 42 (2004) 2555-2568.

[22] X. Liu, P.A. Duckworth, D.K.Y. Wong, Square wave voltammetry versus electrochemical impedance spectroscopy as a rapid detection technique at electrochemical immunosensors, Biosens. Bioelectron. 25 (2010) 1467-1473.

[23] J.M. Lázaro-Martínez, E. Rodríguez-Castellón, D. Vega, G.A. Monti, A.K. Chattah, Solid-state studies of the crystalline/amorphous character in linear poly (ethylenimine hydrochloride) $(\mathrm{PEI} \cdot \mathrm{HCl}$ ) polymers and their copper complexes, Macromolecules 48 (2015) 1115-1125.

[24] E. Gasteiger, C. Hoogland, A. Gattiker, S. Duvaud, M.R. Wilkins, R.D. Appel, The Proteomics Protocols Handbook, Humana Press Inc., New Jersey, 2005.

[25] Z. Yuan, H. Tai, Z. Ye, C. Liu, G. Xie, X. Du, Y. Jiang, Novel highly sensitive QCM humidity sensor with low hysteresis based on graphene oxide (GO)/poly(ethyleneimine) layered film, Sensor. Actuator. B Chem. 234 (2016) 145-154.

[26] P. Sunintaboon, S. Duangphet, P. Tangboriboonrat, Polyethyleneimine-functionalized poly(methyl methacrylate) colloidal nanoparticles for directly coating natural rubber sheet, Colloids Surf. A Physicochem. Eng. Asp. 350 (2009) 114-120

[27] S. McIndoe, A. Love, pH sensor based on polyaniline and aniline-anthranilic acid copolymer films using quartz crystal microbalance and electronic absorption spectroscopy, Polym. Adv. Technol. 19 (2018) 1142-1148.

[28] C. Donley, D. Dunphy, D. Paine, C. Carter, K. Nebesny, P. Lee, D. Alloway, N.R. Armstrong, Characterization of indium-tin oxide interfaces using X-ray photoelectron spectroscopy and redox processes of a chemisorbed probe molecule: effect of surface pretreatment conditions, Langmuir 18 (2002) $450-457$.

[29] A. Corma, H. Garcia, Supported gold nanoparticles as catalysts for organic reactions, Chem. Soc. Rev. 37 (2008) 2096.

[30] J. Wang, J. Li, J. Wei, Adsorption characteristics of noble metal ions onto modified straw bearing amine and thiol groups, J. Mater. Chem. A. 3 (2015) $18163-18170$.

[31] S.P. Chenakin, N. Kruse, Au 4f spin-orbit coupling effects in supported gold nanoparticles, Phys. Chem. Chem. Phys. 18 (2016) 22778-22782.

[32] H. Zhu, M. Du, M. Zou, C. Xu, Y. Fu, Green synthesis of Au nanoparticles immobilized on halloysite nanotubes for surface-enhanced Raman scattering substrates, Dalton Trans. 41 (2012) 10465-10471.

[33] B.C. Choudhary, D. Paul, A.U. Borse, D.J. Garole, Surface functionalized biomass for adsorption and recovery of gold from electronic scrap and refinery wastewater, Separ. Purif. Technol. 195 (2018) 260-270.

[34] N.P.B. Tan, C.H. Lee, P. Li, Green synthesis of smart metal/polymer nanocomposite particles and their tuneable catalytic activities, Polymers (Basel) 8 (2016) 1-14.

[35] K.K. Cline, M.T. McDermott, R.L. McCreery, Anomalously slow electron transfer at ordered graphite electrodes: influence of electronic factors and reactive sites, J. Phys. Chem. 98 (1994) 5314-5319.

[36] M.F. Leal Denis, R.R. Carballo, A.J. Spiaggi, P.C. Dabas, V. Campo Dall' Orto, J.M.L. Martínez, G.Y. Buldain, Synthesis and sorption properties of a polyampholyte, React. Funct. Polym. 68 (2008) 169-181.

[37] M.I. Prodromidis, Impedimetric immunosensors-A review, Electrochim. Acta 55 (2010) 4227-4233. 